\title{
Treatment of obesity in children and adolescents. How nutrition can
}

work?

Luis A. Moreno ${ }^{1}$, María C. Ochoa ${ }^{2}$, Julia Wärnberg ${ }^{3}$, Amelia Marti ${ }^{2}$, J. Alfredo Martínez ${ }^{2}$, Ascensión Marcos ${ }^{3}$

${ }^{1}$ E.U. Ciencias de la salud, Universidad de Zaragoza, Zaragoza (Spain)

${ }^{2}$ Department of Nutrition and Food Sciences, Physiology and Toxicology, Pamplona (Spain)

${ }^{3}$ Immunonutrition Research Group, Dep. Metabolism and Nutrition. Instituto del Frío. Spanish Council for Scientific Research (CSIC), Madrid (Spain).

\section{Author for correspondence and reprint requests:}

Prof. Luis A. Moreno

E.U. Ciencias de la Salud

Universidad de Zaragoza

Domingo Miral s/n

50009 Zaragoza

Spain

Phone: +34976761000 (Ext. 4457)

Fax: +34976761752

E-mail: lmoreno@unizar.es 
Obesity is the most frequent nutritional disorder in transition and developed countries, in which overweight and obesity prevalence has increased in the last decades $(1,2)$. Excess body fat is associated with adverse metabolic complications as well as with relevant short and long-term physical and psychosocial problems (3). The knowledge and understanding of dietary risk factors during specific life periods is needed in order to design preventive measures against the increase in the obesity rates and its consequences (4).

Obesity is the result of an energy imbalance in a susceptible subject. Energy homeostasis is regulated by a complex network of neurohormonal and metabolic processes, which maintain the individual body composition status with a strong inertia. Overweight appears when persistent positive energy imbalances occur for long periods of time. Dietary risk factors for development of childhood and adolescence obesity must be evaluated with longitudinal studies as they give us the possibility to control for confounding factors and to evaluate the effect of a specific factor over time, when the children become obese $(5,6)$.

Obesity in children and adolescents constitute a public health priority and prevention should be the optimal approach. However, prevention programmes that have been adequately assessed do not show enough evidence about their efficacy (7). We should contribute to improve the existing programmes and to develop new ones. However, in the meantime, we must also be ready to treat obese patients following evidence-based best practice criteria.

Research has been ongoing to develop effective intervention studies for obese children (8). However, it is not clear which intervention is the most effective in assisting overweight/obese children to improve body composition without affecting growth rates. Standardized weight-loss interventions should be developed that would incorporate a variety of factors to improve body composition and cardiovascular risk factors (9). Interventions that focus on family involvement use consistent dietary and exercise programs, and behavioural changes should be effective methods for positive body composition changes (10).

The objective of this article is to review the available knowledge on dietary risk factors for the development of childhood obesity, to discuss different dietary treatment strategies, and to propose an evidence based approach to treat obese adolescents. 


\section{Dietary risk factor for obesity development}

There are few longitudinal studies that relate overweight development and energy intake or diet composition during a controlled period in children and adolescents (11-15). Longitudinal studies carried out during long periods of time have not shown that energy intake or diet composition is related to significant differences in childhood weight gain (11-13). Protein intake during the early postnatal months has been related to increased body size and adiposity due to higher plasma levels of insulin and IGF-1 levels $(16,17)$ and breastfeeding is associated with a lower risk of overweight and obesity in later years (18-23). Both energy and protein intakes are lower in breast-fed infants as compared with formula-fed infants, providing indirect evidence of the importance of these factors. Mechanisms by which breastfeeding affects the risk of overweight remain still unclear.

To assess what are the real dietary risk factors of childhood obesity, instead of a simple energy intake, we must take into account food consumption and contemporary eating patterns (elevated consumption of bakery foods, sweetened beverages, sweets or low-quality foods, the low consumption of fruit and vegetables, daily meal patterns and energy intake distribution) as well as physical activity patterns, socio-cultural and economic status.

The food composition of the diet has an influence on eating behaviour, and vice versa. Palatability of meals and high energy density foods are linked, promoting more energy intake due to food consumption quantity and quality. After an excessive intake of high energy density foods, compensatory eating responses may be not sufficient to suppress hunger or to delay eating. However, eating low-energy-dense foods (such as fruits, vegetables, and soups) maintains satiety, while reducing energy intake (24).

The frequency of daily meals has been inversely associated with the prevalence of overweight (25); however, no enought data from longitudinal studies are available. Consumption of snacks between meals and the contribution of snacking to total daily energy and fat intake have increased among children and adolescents during the last decade. It is difficult so far to obtain reliable information on relationships between snacking and the risk of obesity in young pepople.

The consumption of soft drinks has also increased in children over the past decades. The greater the sweetened drink consumption, the greater is the weight gain (26). This is explained by the observation that children fail to reduce solid food 
consumption, which is needed in order to compensate for the caloric contribution of sweetened drinks. In addition, certain types of caloric sweeteners, such as high-fructose corn syrup, might, in and of themselves, contribute to increased weight gain due to their influence on lipogenesis, insulin secretion or leptin production (27).

When eating in restaurants, individuals tend to consume a large amount of food and they tend to choose high-energy foods. Both the frequency of fast food consumption and the amount of energy intake from fast foods are increasing due to a variety of factors: big portion sizes, palatable and cheap foods, affordable prizes, the attractiveness of fast food and easy access to restaurants attractive for children and adolescents (28). There are no longitudinal studies on the direct relationship between fast food intake and the risk of overweight development in children.

Nowadays, the portion sizes of some food items (snacks, soft drinks, french fries, hamburgers, etc.) are on the increase and this is in parallel with the rise in the prevalence of obesity. It has been shown that children's energy intake increases when larger portions are offered (29). There are neither cross-sectional nor longitudinal studies that have found associations between food portion size and the risk of overweight development in children.

To date, with the exception of infants, longitudinal studies in children have not found clear causal associations between energy intake or diet composition and overweight development. Among formula or mixed-fed infants, not in those breastfed, increases in total energy and food intake showed an association with a risk of overweight at 3-5 years of age. Breastfeeding also seems to be protective and associated with a lower risk of overweight and obesity in later years.

Despite the fact that snacking, fast food consumption and big food portion sizes have been associated with non-healthy habits and excessive energy/fat intake, none of these factors have been significantly related to obesity in cross-sectional or longitudinal studies. Probably, a combination of all these factor, and other related ones could, at the end , be related with obesity onset in children and adolescents. 


\section{Effect of macronutrient distribution of dietary intake on childhood obesity}

The different macronutrient distribution of the diet is important regarding the development of childhood and adolescents obesity (30). The recommended dietary macronutrient content in diet for children aged 4-18 are 25-35\% of energy from fat, 10$30 \%$ from protein and 45-65\% from carbohydrates according to the Institute of Medicine (31, 32). In the last years, consumption data from United States indicate that the percent of calories from fat has decreased (although total fat grams increased) and percent from carbohydrate has also increased $(33,34)$. Moreover, this rise in carbohydrate intake appears to be due to an increased consumption of refined grain products and soft drinks (35), whereas intakes of total fiber have decreased (36).

Most of the dietary fat in the Canadian children (as a proxy of Western population) comes from sandwiches, sweet bakes goods, milk, salads with dressing, cheese, pasta, french fries, eggs and margarine (29). Fat intake is thought to be linked to an increase in food intake stimulation (hyperphagia) due to its low capacity of saciety, high palatability, energy density and poor metabolic regulation (37). Indeed, there are studies that show a positive association between the percentage of energy intake as dietary fat and markers of adiposity in children and adolescents (38), however in some longitudinal studies the results are negative (39). It must be taken into account that freeliving studies are often biased by the food intake mis-reporting (40). In this context, a controlled trial showed that meal-induced thermogenesis in children is higher after a low-fat meal compared to a high-fat meal and postpandrial fat storage is also higher (41). Moreover, low fat diets lead to long term weight loss and beneficial changes in lipids, blood glucose, glycaemic control, and blood pressure in children and adolescents (42).

In the last years, the type of dietary fat is receiving more attention regarding its association with obesity. Obese children consumed a higher amount of saturated fat compared to non-obese children (43) and saturated fat intake has been associated with greater body mass index (44). Futhermore, it has been shown that the polyunsaturated fatty acid intake results in a minor increase in body fat compared to monounsaturated and saturated fatty acids intake (45). Although energy density is almost the same, the effect of each type of fat on obesity requires further investigation given their different physiological effects (46).. Since in Western societies infants are exposed to high n-6, saturated and trans fatty acids and low n-3 fatty acids, this diet composition may 
contribute to oxidative stress and heightened inflammatory responses in young children (47).

Since carbohydrates have significantly lower energy density compared to fat, it has been suggested that carbohydrate intake may be inversely related to obesity (46). Indeed, there are some cross-sectional and longitudinal studies that have associated lower intake of carbohydrates with obesity $(48,49)$. But few studies among children have been focused on types of carbohydrates and its relationship with obesity

The role of fiber could be important in childhood obesity, but only a small number of studies have specifically examined fiber intake in children. Some dietary surveys show that low consumption of fruit and vegetables among young people increases the energy density of the overall diet (50) and the available evidence suggests that consumption of fiber potentially could play a useful role in weight maintenance (51). Children ussually have a suboptimal number of servings from fruit and vegetable groups (52), what represents that the intake of fiber, vitamins and minerals is bellow the recommended dietary allowances. Some social programs, like the National School Lunch Program (NSLP) (53) have had a positive impact on intakes of micronutrients such as vitamin $\mathrm{A}, \mathrm{B}_{12}, \mathrm{~B}_{6}$, riboflavin, niacin, calcium, phosphorus, magnesium and zinc (54). Programs focused on the study and improvement of children and adolescents nutrition are good tools. In this sense, in Spain a program of study and intervention, the EVASYON study, is being with obese adolescents.

Other factor concerning the diet composition related to carbohydrates metabolism is the glycemic index and the glycemic load. Glycemic index represents the relative rate of entry of glucose into the bloodstream compared to a reference carbohydrate, whereas glycemic load represents both the quality of the carbohydrate containing food and the quantity consumed (55). There are some studies that have associated the glycemic index and glycemic load with obesity in children $(56,57)$. Moreover, it has been shown that after a high glycemic index meal, children and adolescents had a greater voluntary energy intake than after low glycemic index meal (58). Design of a low fat diet can be consistent with low glycemic index. Such a diet provides the best chance for long term change to healthy eating habits, although palatability could be a problem (42).

Few studies have investigated the role of protein intake in childhood and adolescent obesity. There are reports about the association between high protein intake and a early adiposity rebound that has been related with childhood obesity (59). But 
there are not available data to assess the association between obesity and protein intake in older children or adolescents.

Protein is a highly satiating macronutrient and some authors have suggested that low-carbohydrate/high protein diets could be a starting point for poorly motivated patients to loose weight (60). There are also some trials that have been focused on lowcarbohydrate diets vs. energy-restricted low-fat diets $(60,30)$. The first trial of this type in children was reported by Pena et al. (61). They treated 104 children from 6 to 14 years old with an ad libitum ketogenic low carbohydrate (<20g/day) diet or with a balanced hypocaloric diet. After 8 weeks of dietetic treatment, in the group with the low carbohydrate diet the percentage of overweight subjects decreased more than in the hypocaloric group. In the study of Sondike et al. (62) they included 20 subjects in the group of low carbohydrate diet and 19 in the group of low-fat diet. Before 12 weeks of treatment, subjects with the low carbohydrate diet had lost more weight than subjects with the low fat diet. Other similar study, performed only with 19 subjects, but with one year follow-up period with hypocaloric balanced diet did not show differences in weight loss weight between the two groups after one year since the low carbohydrate diet (63).

It appears that in the short-term, subjects with low-carbohydrate diets have a higher decrease in BMI, but more research would be heeded to obtain conclusions in long-term time period $(60,64)$. Moreover, some side effects, such as headache, constipation, halitosis, fatigue, and deterioration of lipid profile should be taken into account whit this type of diets (42).

Dietary interventions are aimed to reduce the intake of high-fat foods, simple sugars, and sweetened beverages and at to increase the intake of low-calorie high-fiber foods such as fruits, vegetables, and whole grains (64). Some studies have performed intervention trials with balanced hypocaloric diets in children and adolescents. Those studies usually include a parallel moreover to increase physical activity, including behavioural therapy, to modify and reducing sedentary behaviour and cognitive therapy (65). A recently published meta-analisys found eight randomised controlled trials of intervention for children obesity, where a 'true' control arm was used and results were reported post intervention that included 268 subjects (66). Most of that studies used the traffic light diet (67) or calorie exchange programs and the pooled standardised mean difference of BMI after treatment was -1.82 , 95\% CI (-2.40 to -1.23).

For obese children aged 7 years or younger who have no secondary complications, the accepted standard practice is denoted to weight maintenance. Weight 
loss is recommended for those older than 7 years with a BMI between the 85th percentile and 95th percentile who have a secondary complication of obesity and for those with BMI at or above the 95th percentile. The initial aim in children who have to reduce their weight is a rate of approximately $0.45 \mathrm{~kg}$ per month (68).

Other factors may modify weight loss by dieting are sex, age, initial body weight, race, genetics, regional fat deposition, lifestyle and family factors etc, which must be taken into account to explain the variability in the outcomes of different treatment with low-energy diets $(30,64,69)$. Therefore, more research is needed about the impact of diets with different fuel substrates and food item on the characteristics of the weight-loss process.

\section{Obesity treatment for obese adolescents}

Prevention is a keystone to slow down, if not stop, the obesity epidemic, but also the treatment is an important part of the multilevel response needed. Although there is a growing awareness of the long-term health complications of obesity, yet many paediatricians do or can not offer effective treatment to obese adolescents in the absence of co-morbid conditions. Successful methods to treat paediatric overweight remain elusive, but together with previously discussed energy intake reduction a behaviour modification, and family involvement to encourage increased physical activity and a reduced sedentary activity are other assumed cornerstones of adolescent weight management and are being actively investigated. Successful behavioural programs are labour intensive, are not yet translated into versions that can be easily applied on the primary care level, and require intensive parental involvement.

Even though obesity is now viewed as a chronic disorder that requires continued treatment; very few controlled studies lasting more than a few weeks have examined the efficacy of treatment programmes in primary care centres, to reduce body weight and changes of habits and behaviour in overweight and obese children or adolescents. With the objective of developing a sustainable long-term multidisciplinary obesity treatment program adapted to Spanish primary care centres, the EVASYON (Development, implementation and evaluation of the efficacy of a treatment programme for adolescents with overweight and obesity: Integral education on nutrition and physical activity [Sp: 
Desarrollo, aplicación y evaluación de la eficacia de un programa terapéutico para adolescentes con sobrepeso y obesidad: educación integral nutricional y de actividad física]) study was designed and is now assessed in 5 centers of paediatrics in the cities of Granada, Madrid, Pamplona, Santander and Zaragoza, and financed by the Spanish Ministry of Health.

The one year's treatment of obese adolescents in primary care setting has a multidisciplinary approach and includes nutritional and individual diet counselling, modification of diet and caloric content, increased physical activity and exercise, and active participation in appropriate activities, group therapy focused on changing behaviours, support and encouragement for making these changes and to follow treatment recommendations. Treatment goals are realistic, focused on modest reduction of intake, changes in eating habits, and the incorporation of a healthy active lifestyle. The clinical setting of this multidisciplinary programme includes the involvement, a part from the paediatricians, of nutritionists, qualified mental health professionals and physical activity and exercise specialists, following a standardized methodology and protocols established specially for this study.

Successful methods to treat paediatric overweight and obesity remain a difficult task, but we should not forget that not only weight reduction is the aim of any programme, but to change lifestyles and to reduce long-term risk factors associated with obesity. 


\section{References}

1. Hedley AA, Ogden CL, Johnson CL, et al. Prevalence of overweight and obesity among US children, adolescents, and adults, 1999-2002. JAMA 2004; 291: 2847-50.

2. Moreno LA, Mesana MI, Fleta J, Ruiz JR, González-Gross MM, Sarría A, Marcos A, Bueno $\mathrm{M}$ and the AVENA Study Group. Overweight, obesity and body fat composition in Spanish adolescents. The AVENA Study. Ann Nutr Metab 2005; 49: 71-76.

3. Ebbeling C, Pawlak DB, Ludwig DS. Childhood obesity: public-health crisis, common sense cure. Lancet 2002; 360: 473-482.

4. Ahrens W, Bammann $\mathrm{K}$, de Henauw S, et al. Understanding and preventing childhood obesity and related disorders - IDEFICS: A European multilevel epidemiological approach. Nutr Metab Cardiovasc Dis 2006; 16: 302-8.

5. Rodríguez G, Moreno LA. Is dietary intake able to explain differences in body fatness in children and adolescents? Nutr Metab Cardiovasc Dis 2006; 16: 294-301.

6. Moreno LA, Rodríguez G. Dietary risk factors for development of childhood obesity. Curr Op Clin Nutr Metab Care 2007; 10: 336-341.

7. Summerbell CD, Waters E, Edmunds LD, et al. Interventions for preventing obesity in children. Cochrane Database Syst Rev 2005; 3: CD001871.

8. Epstein LH, Myers MD, Raynor HA, Saelens BE. Treatment of pediatric obesity. Pediatrics 1998; 101: 554-70.

9. Steinbeck KS, Baur LA, Morris AM, Ghersi D. A proposed protocol for the development of a register of trials of weight management of childhood overweight and obesity. Int J Obes (London) 2006; 30: 2-5.

10. Moreno LA. Interventions to improve cardiovascular risk factors in obese children. $\mathrm{J}$ Pediatr Gastroenterol Nutr 2006; 43: 433-435.

11. Maffeis C, Talamini G, Tato L. Influence of diet, physical activity and parents' obesity on children's adiposity: a four-year longitudinal study. In J Obes 1998; 22: 758-764.

12. Bogaert N, Steinbeck KS, Baur LA, et al. Food, activity and family--environmental vs biochemical predictors of weight gain in children. Eur J Clin Nutr 2003; 57: 1242-1249. 
13. Magarey AM, Daniels LA, Boulton TJ, Cockington RA. Does fat intake predict adiposity in healthy children and adolescents aged 2--15 y? A longitudinal analysis. Eur J Clin Nutr 2003; 55: 471-481.

14. Berkey CS, Rockett HR, Field AE, et al. Activity, dietary intake, and weight changes in a longitudinal study of preadolescent and adolescent boys and girls. Pediatrics 2000; 105: E56.

15. Ong KK, Emmett PM, Noble S, et al. Dietary energy intake at the age of 4 months predicts postnatal weight gain and childhood body mass index. Pediatrics 2006; 117: e503-8.

16. Parizkova J, Rolland-Cachera MF. High proteins early in life as a predisposition for later obesity and further health risks. Nutrition 1997; 13: 818-819.

17. Scaglioni S, Agostoni C, Notaris RD, et al. Early macronutrient intake and overweight at five years of age. Int J Obes 2000; 24: 777-781.

18. Gillman MW, Rifas-Shiman SL, Camargo CA, et al. Risk of overweight among adolescents who were breastfed as infants. JAMA 2001; 285: 2461-2467.

19. Bogen DL, Hanusa BH, Whitaker RC. The effect of breast-feeding with and without formula use on the risk of obesity at 4 years of age. Obes Res 2004; 12: 1527-1535.

20. Owen CG, Martin RM, Whincup PH, et al. Effect of infant feeding on the risk of obesity across the life course: a quantitative review of published evidence. Pediatrics 2005; 115: 1367-1377.

21. Heinig MJ, Nommsen LA, Peerson JM, et al. Energy and protein intakes of breastfed and formula-fed infants during the first year of life and their association with growth velocity: the DARLING Study. Am J Clin Nutr 1993; 58: 152-161.

22. Harder T, Bergmann R, Kallischnigg G, Plagemann A. Duration of breastfeeding and risk of ovwerweight: a meta-analysis. Am J Epidemiol 2005; 162: 397-403.

23. Arenz S, Ruckerl R, Koletzko B, von Kries R. Breast-feeding and childhood obesity-a systematic review. Int J Obes Relat Metab Disord 2004; 28: 1247-1256.

24. Ello-Martin JA, Ledikwe JH, Rolls BJ. The influence of food portion size and energy density on energy intake: implications for weight management. Am J Clin Nutr 2005; 82 (1 Suppl): 236S-241S.

25. Toschke AM, Kuchenhoff H, Koletzko B, von Kries R. Meal frequency and childhood obesity. Obes Res 2005; 13: 1932-1938.

26. Ochoa MC, Moreno-Aliaga MJ, Martínez-González, et al. Predictor factors for childhood obesity in a Spanish case control study. Nutrition 2007; 23:379-84. 
27. Bray GA, Nielsen SJ, Popkin BM. Consumption of high-fructose corn syrup in beverages may play a role in the epidemic of obesity. Am J Clin Nutr 2004; 79: 537543.

28. Bowman SA, Gortmaker SL, Ebbeling CB, et al. Effects of fast-food consumption on energy intake and diet quality among children in a national household survey. Pediatrics 2004; 113: 112-118.

29. Orlet Fisher JO, Rolls BJ, Birch LL. Children's bite size and intake of an entree are greater with large portions than with age-appropriate or self-selected portions. Am J Clin Nutr 2003; 77: 1164-1170.

30. Abete I, Parra MD, Zulet MS et al. Different dietary strategies for weight loss in obesity: role of energy and macronutrient content. Nutr Rev Res 2006; 19: 5-17.

31. Canadian Community Health Survey 2004. Overview of Canadian eating habits by Didier Garriguet. Cat. No. 82-620-MIENo. 2. http://www.Statcan.ca/english/reach/ 82-620-MIE/82-620-MIE2006002.pdf.

32. Instute of Medicine. Dietary reference intakes for energy carbohydrate, fiber, fat, fatty acids, cholesterol, protein and amino acids. National Academy Press. Washington DC 2005.

33. Willett WC. Is Dietary Fat a Major Determinant of Body Fat? Am J Clin Nutr 1998; 67: 556S-562S.

34. Morton JF, Guthrie JF. Changes in Children's Total Fat Intakes and their Food Group Sources of Fat, 1989-91 versus 1994-95: Implications for Diet Quality. Fam Eco Nutr Rev 1998; 11: 44-57.

35. Hill JO, Peters JC. Environmental Contributions to the Obesity Epidemic. Science 1998; 280: 1371-1374.

36. Saldanha JG, Fiber in the Diet of U.S. Children: Results of National Surveys. Pediatrics 1995; 96: 994-997.

37. Labayen I, Martínez JA. [Diet macronutrient distribution and body weight regulation: role of lipid intake in obesity]. An Sis San Nav 2002; 25: 79-90.

38. Maffeis C, Pinelli L, Schultz Y. Fat intake and adiposity in 8-11 year-old obese children . Int J Obes. 1996; 20:170-174.

39. Johansson G, Wikman A, Ahren AM, et al. Underreporting of energy intake in repeated 24-hour recalls related to gender, age, weight status, day of interview, educational level, reported food intake, smoking habits and area of living. Public Health Nutr. 2001; 4: 919-27. 
40. Magarey AM, Daniels LA, Bouton TJC, et al. Does fat intake predict adiposity in healthy children and adolescents aged 2-15y? A longitudinal analysis. Eur J Clin Nutr 2001; 55: 471-481.

41. Maffeis C, Schutz Y, Grezzani A, et al. Meal-induced Thermogenesis and Obesity: Is a Fat Meal a Risk Factor for Fat Gain in Children?. J Clin End Metab 2001; 86: 214-219.

42. Avenell A, Sattar N, Lean M, et al. Management: Part I-Behaviour change, diet and activity. BMJ 2006;333:740-743.

43. Gillis LJ, Kennedy LC, Gillis AM, et al. Relationship between Juvenile Obesity, Dietary Energy and Fat Intake and Physical Activity. Int J Obes Relat MetD isord 2002; 26: 458-463.

44. Guillaume M, Lapidus L, Lambert A. Obesity and Nutrition in Children. The Belgian Luxembourg Child Study IV. Eur J Clin Nut 1998; 52: 323-328.

45. Doucet E, Almeras N, White MD, et al. Dietary fat composition and human adiposity. Eur J Clin Nutr 1998; 52: 2-6.

46. Newby PK. Are dietary intakes and eating behaviors related to childhood obesity? A comprehensive review of the evidence. J Law, Med Eth 2007; 35: 35-60.

47. Innis SM. Dietary lipids in early development: relevance to obesity, immune and inflammatory disorders. Curr Opin Endocrinol Diabetes Obes. 2007; 14: 359-64.

48. Gibson SA. Associations between energy density and macronutrient composition in the diets of pre-school children: sugar vs starch. Int J Obes 2000; 24: 633-638.

49. Gutmanis. Adolescents' Low-carbohydrate-density Diets are Related to Poorer Dietary Intakes. J Am Diet Assoc 2005; 105: 1783-1788.

50. Lobstein T, Baur L, Uauy R. Obesity in children and young people: a crisis in publich health. Obes Rev 2004; 5: 4-85.

51. Kimm SY. The role of dietary fiber in the development and treatment of childhood obesity. Pediatrics. 1995; 96: 1010-4.

52. Kenedy E, Shaw A, Davis C. Essential fatty acids and USDA's Food Guide Pyramid. Am J Clin Nutr 1995; 62: 645-647.

53. Nicklas TA, O’Neil CE, Berenson GS et al. Nutrient contribution of breakfast, secular trends, and the role of ready-to-eat cereals: a review of data from the Bogalusa Heart Study. Am J Clin Nutr 1998; 67: 757S- 763S. 
54. Gordon AR, Devaney BL, Burghardt JA et al. Dietary effects of the National School Lunch Program and the School Breakfast Program. Am J Clin Nutr 1995; 61: 221S231S.

55. Bell SJ, Sears B. Low-glycemic-load diets: impact on obesity and chronic diseases. Crit Rev Food Sci Nutr 2003; 43: 357-377.

56. Ebbeling CB, Leidig MM, Sinclair KB, et al. A Reduced-Glycemic Load Diet in the Treatment of Adolescent Obesity. Arch Ped Adol Med 2003; 157: 773-779.

57. Spieth LE, Harnish JD, Lenders CM, et al. A low-glycemic index diet in the treatment of pediatric obesity. Arch Pediatr Adolesc Med 2000; 154:947-951.

58. Ludwig DS, Majzoub JA, Al-Zahrani A, et al. High Glycemic Index Foods, Overeating, and Obesity. Pediatrics 1999; 103: E26.

59. Rolland-Cachera MF, Deheeger M, Akrout M, et al. Influence of macronutrients on adiposity development: a follow-up study of nutrition and growth from 10 months to 8 years of age. Int J Obes 1995; 19:573-578.

60. Gibson LJ, Peto J, Warren JM et al. Lack of evidence on diets for obesity for children: a systematic review. Int J Epid 2006; 35:1544-1552.

61. Pena L, Pena M, Gonzalez J et al. A comparative study of two diets in the treatment of primary exogenous obesity in children. Acta Paediatr Acad Sci Hung. 1979; 20: 99-103.

62. Sondike SB, Copperman N, Jacobson MS et al. Effects of a low- carbohydrate diet on weight loss and cardiovascular risk factor in overweight adolescents. J Pediatr 2003; 142: 253-58.

63. Figueroa-Colon R, von Almen TK, Franklin FA et al. Comparison of two hypocaloric diets on obese children. Am J Dis Child 1993; 147: 160-166.

64. Singhal V, Schwenk WF, Kumar S et al. Evaluation and management of childhood and adolescent obesity. Mayo Clin Proc. 2007; 82: 1258-1264.

65. Joanna Briggs Institute. Effective dietary interventions for managing overweight and obesity in children. Nurs N Z. 2007; 13: 30-31.

66. Collins CE, Warren JM, Neve M et al. Systematic review of interventions in the management of overweight and obese children which include a dietary component. Int J Evid Based Healthc. 2007; 5: 2-53.

67. Epstein LH, Myers MD, Raynor Haet al. Treatment of pediatric obesity. Pediatrics 1998; 101: 554-70. 
68. Barlow SE, Dietz WH. Obesity evaluation and treatment: Expert Committee recommendations. Pediatrics. 1998; 102: E29.

69. MC Ochoa, Marti A, Martínez JA. [Obesity studies in candidate genes] Med Clin (Barc). 2004 Apr 17;122:542-51 